\title{
Design of Flexible 3.2 GHz Rectangular Microstrip Patch Antenna for S-Band Communication
}

\author{
Teguh Praludi a, *, Yana Taryana a , Ken Paramayudha a, Budi Prawara a, Yusnita \\ Rahayu ${ }^{b}$, Chaeriah Bin Ali Wael a, Yaya Sulaeman a, Bagus Edy Sukoco a, Ros \\ Sariningrum ${ }^{a}$, Hendrawan Kurniadin ${ }^{a}$, Wahid Nova Nugraha ${ }^{b}$ \\ a Research Center for Electronics and Telecommunication \\ National Research and Innovation Agency \\ Kampus BRIN, Jl. Sangkuriang Gedung 10, Lantai 3, Cisitu \\ Bandung, Indonesia \\ ${ }^{b}$ Department of Electrical Engineering \\ Riau University \\ Jl. HR. Soebrantas Panam No.km 12, RW.5, Simpang Baru, Panam \\ Pekanbaru, Indonesia
}

\begin{abstract}
This paper presents the design, simulation, realization and analysis of flexible microstrip patch antenna for S-band applications. The proposed design also adopts the conformal structure by utilizing flexible substrate. Conformal or flexible structure allows the antenna to fit with any specified shape as desired. The antenna patch dimensions is $43 \mathrm{~mm} \times 25 \mathrm{~mm}$ without SMA connector. The patch is etched on the flexible dielectric substrate, pyralux FR 9111, with a relative dielectric constant of $\varepsilon_{\mathrm{r}}=3$ and the thickness of substrate, $h=0.025 \mathrm{~mm}$. The antenna is designed to resonate at $3.2 \mathrm{GHz}$. The return loss $\left(\mathrm{R}_{\mathrm{L}}\right)$ of the simulation is $-35.80 \mathrm{~dB}$ at the center frequency of $3.2 \mathrm{GHz}$. The fabricated antenna prototype was measured at different bending angles scenarios including $0^{\circ}, 30^{\circ}, 60^{\circ}$, and $90^{\circ}$. The measurement of antenna prototype shows that the center frequency is shifted to the higher frequency of $3.29 \mathrm{GHz}$, compared to the simulation result. Among these scenarios, measurement at bending angle of $90^{\circ}$ gives the best performance with $R_{\mathrm{L}}=-31.38 \mathrm{~dB}$ at $3.29 \mathrm{GHz}$, the bandwidth is $80 \mathrm{MHz}$, and the impedance $Z_{\mathrm{A}}=48.36+\mathrm{j} 2.04 \Omega$. Despite a slight differences from simulation results, the designed antenna still performs well as expected.
\end{abstract}

Keywords: Microstrip patch antenna, rectangular shaped antenna, conformal antenna, flexible antenna, S-band communication, flexible substrate, pyralux FR 9111.

\section{INTRODUCTION}

S-band frequencies are commonly used for radar and satellite communication [1], as well as other applications including Wi-Fi 802.11b and 802.11g [2], WiMAX 802.16d [2], microwave ovens [3], and optical communication with the wavelength between $1460 \mathrm{~nm}$ to $1530 \mathrm{~nm}$ [4]. Several applications in aerospace or satellite communications require antenna structure to be lightweight, has low profile, and ease of manufacturing or low cost. Microstrip patch antenna (MPA) offers these merits. Furthermore, MPA has the flexibility and conformability to mounting devices, thus, it is fit for high-speed moving objects such as satellites, various space aircraft, rockets, and missiles [5].

Microstrip antenna have three important parts, which are including patch, substrate dielectric, and the ground plane, as shown Figure 1. The patch of microstrip antenna structure is usually formed on the top patch layer with the shape of varies, but in general the basic shape of

\footnotetext{
* Corresponding Author.

Email: teguhpraludi@gmail.com

Received: October 30, 2021 ; Revised: December 11, 2021

Accepted: December 21, 2021 ; Published: December 31, 2021

Open access under CC-BY-NC-SA

(C) 2021 PPET - LIPI
}

the patch is a square shape, triangle and circle. Patch on the microstrip antenna has function to radiate electromagnetic waves in free air. Copper $(\mathrm{Cu})$ is generally used as patch material.

In this paper, we designed, fabricated, and measured a single patch rectangular microstrip antenna with the resonant frequency of $3.2 \mathrm{GHz}$. The proposed antenna structure also belong to the class of conformal antennas. Several previous studies proposed MPA for satellite communication. Even though the designed antenna that proposed in this study is intended not only for satellite communication applications, the review is aimed to emphasize MPA design for high-speed moving object. In [6], rectangular patch antenna with resonant frequency of $2.48 \mathrm{GHz}$ and the bandwidth of $40.3 \mathrm{MHz}$ was realized

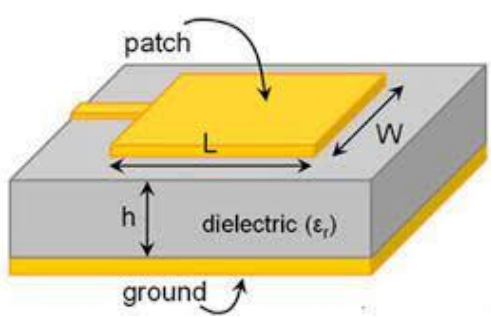

Figure 1. Antenna microstrip with substrate, patch and ground plane. 
using Roger RT Duroid 5880 for IRNSS Application. A reconfigurable rectangular patch antenna for cubesat satellites application was proposed in [7]. A square patch antenna with circular polarization was proposed in [8] for satellite communication with center frequency of 2.595 GHz. Most previous studies did not incorporate the conformal characteristic of MPA into their antenna design for S-band application, in general. Thus, in this study, we proposed rectangular patch that realized on flexible substrate, pyralux FR 9111, to get conformal structure. The use of flexible substrates will allow the antenna to conform or bend into a desired shape and will significantly reduce the weight antenna.

The organization of the paper is as follows: antenna design and realization are described in section II, while simulation and measurement results are presented in section III, before the paper is concluded.

\section{MATERIALS AND METHODS}

\section{A. Antenna Design}

In designing rectangular microstrip patch antenna for communication application, the resonant frequency $\left(f_{\mathrm{c}}\right)$, dielectric constant and the thickness of the substrate need to be chosen carefully. The resonant frequency of the antenna determined by the patch dimensions and substrate dielectric constant as written in (1), where $f_{\mathrm{c}}$ is resonant frequency $(\mathrm{Hz})$, and $c$ is speed of light in vacuum $\left(3 \times 10^{8} \mathrm{~m} / \mathrm{sec}\right) . \varepsilon_{\mathrm{r}}, L$, and $W$ denote substrate dielectric constant, length (m) and width (m) of microstrip patch antenna. The choice of substrate thickness brings effect on bandwidth and radiation efficiency, while substrate permittivity affects transmission efficiency and circuit miniaturization since the substrate wavelength is inversely proportional to the square root of its permittivity as expressed in (2) [9]-[10].

$$
\begin{gathered}
f_{c}=\frac{c}{2 \pi \sqrt{\varepsilon_{r}}} \sqrt{\left(\frac{\pi}{L}\right)^{2}+\left(\frac{\pi}{W}\right)^{2}} \\
\lambda_{s}=\frac{\lambda_{0}}{\sqrt{\varepsilon_{r}}} \\
\lambda_{0}=\frac{c}{f_{c}}
\end{gathered}
$$

where $\lambda_{\mathrm{s}}$ and $\lambda_{0}$ are wavelength in the substrate $(\mathrm{m})$ and wavelength in the air (m).

After specifying the resonant frequency, substrate permittivity and substrate thickness, these following steps are commonly used for designing the antenna [11][12]:

\section{1) Determine the size of patch}

- Calculate the width of the patch $(W)$

$$
W=\frac{c}{2 f_{c}} \sqrt{\frac{2}{\varepsilon_{r}+1}}
$$

- Calculate effective dielectric constant $\left(\varepsilon_{\text {reff }}\right)$

$$
\varepsilon_{\text {reff }}=\frac{\varepsilon_{r}+1}{2}+\frac{\varepsilon_{r}-1}{2}\left[\frac{1}{\sqrt{1+\frac{12 h}{W}}}\right]
$$

- Calculate the length extension $(\Delta L)$

$$
\Delta L=0.412 h \frac{\left(\varepsilon_{\text {reff }}+0.3\right)\left(\frac{W}{h}+0.264\right)}{\left(\varepsilon_{\text {reff }}-0.258\right)\left(\frac{W}{h}+0.8\right)}
$$

- Calculate the actual length of patch $(L)$

$$
L=\frac{1}{2 f_{c} \sqrt{\varepsilon_{\text {reff }}} \sqrt{\mu_{0} \varepsilon_{0}}}-2 \Delta L
$$

2) Determine the size of ground plane

$$
\begin{gathered}
L_{g}=6 h+L \\
W_{g}=6 h+W
\end{gathered}
$$

where $L_{\mathrm{g}}$ and $W_{\mathrm{g}}$ are the length and the width of ground plane, respectively.

\section{3) Determine the characteristic impedance}

The characteristic impedance for microstrip transmission line of width $w_{1}$ is determined by formula (12).

$$
\begin{gathered}
\frac{w_{1}}{h}=\left[\frac{e^{H^{\prime}}}{8}-\frac{1}{4 e^{H^{\prime}}}\right] \\
H^{\prime}=\frac{Z_{0 \sqrt{2\left(\varepsilon_{r}+1\right)}}}{119.9}+\frac{1}{2}\left(\frac{\varepsilon_{r}-1}{\varepsilon_{r}+1}\right)\left(\ln \frac{\pi}{2}+\frac{1}{\varepsilon_{r}} \ln \frac{4}{\pi}\right) \\
Z_{0} \\
= \begin{cases}\frac{120 \pi \sqrt{\varepsilon_{\text {reff }}}}{h}+1.393+0.667 \ln \left[\frac{w_{1}}{h}+1.444\right] & \text { for } \frac{w_{1}}{h} \geq 1 \\
\frac{60}{\sqrt{\varepsilon_{\text {reff }}}} \ln \left[\frac{8 h}{w_{1}}+\frac{w_{1}}{4 h}\right] & \text { for } \frac{w_{1}}{h} \leq 1\end{cases}
\end{gathered}
$$

We consider the antenna realization on flexible substrate i.e., pyralux FR 9111 with dielectric constant, $\varepsilon_{\mathrm{r}}=3$, and the thickness, $h=0.025 \mathrm{~mm}$. The patch of the microstrip antenna and full ground plane on the bottom of the substrate uses copper with thickness of $0.035 \mathrm{~mm}$. This work is intended to design rectangular single patch antenna with resonant frequency of $3.2 \mathrm{GHz}$. The initial dimensions of the antenna from the calculation is shown in Table 1. This initial size is then optimized through simulation to get optimal performance before the antenna is being fabricated.

The simulations are conducted using Advanced Design System (ADS) 2019 software at range frequency of $3-3.4 \mathrm{GHz}$ with the mesh resolution of 120 cell/wavelength. For optimization, the dimensions of the patch antenna are adjusted to get optimum results of antenna characteristics. Figure 2 depicts top view of the final proposed antenna geometry. The size of the patch antenna is $43 \times 25 \mathrm{~mm}$. The detailed size of each segment of final designed antenna are enlisted in Table 2. 
TABLE 1

INITIAL DIMENSIONS OF DESIGNED ANTENNA

\begin{tabular}{|l|l|}
\hline Parameter & Dimensions $(\mathbf{m m})$ \\
\hline Patch size $(\boldsymbol{W} \times \boldsymbol{L})$ & $33.15 \times 27.06$ \\
\hline Ground plane size $\left(\boldsymbol{W}_{\mathrm{g}} \times \boldsymbol{L}_{\mathrm{g}}\right)$ & $33.29 \times 27.21$ \\
\hline
\end{tabular}

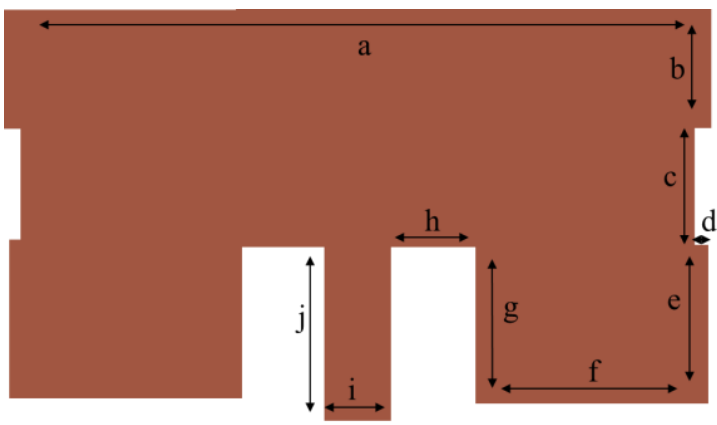

Figure 2. Simulated antenna geometry

TABLE 2

FINAL DIMENSIONS OF DESIGNED ANTENNA

\begin{tabular}{|l|l|}
\hline Parameter & Dimensions (mm) \\
\hline a & 43 \\
\hline b & 7.5 \\
\hline c & 7.5 \\
\hline d & 1 \\
\hline e & 10 \\
\hline f & 14 \\
\hline g & 10 \\
\hline h & 5.5 \\
\hline i & 4 \\
\hline j & 11 \\
\hline
\end{tabular}

\section{B. Antenna Realization}

The antenna is fabricated using pyralux FR 9111 with dielectric constant, $\varepsilon_{\mathrm{r}}=3$, and the thickness, $h=$ $0.025 \mathrm{~mm}$. Pyralux is chosen due to its flexibility, lightness, and low cost in manufacturing technique. A rectangular shaped patch antenna is etched on the top of pyralux substrate. The ground plane is placed on the bottom side of the substrate. The shape of the indentation in the design is intended to get the desired bandwidth and working frequency. This prototype is expected work well at S-band, particularly with operating frequency of 3.2 $\mathrm{GHz}$. The prototype of antenna realization is shown in Figure 3.

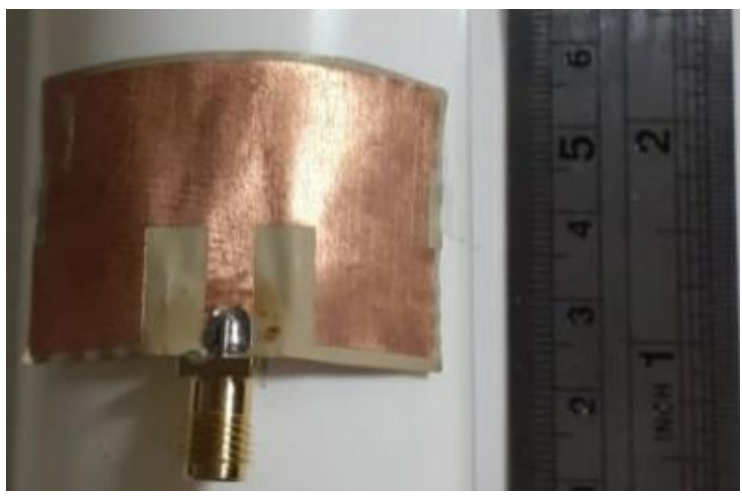

Figure 3. Realization of conformal microstrip antenna

\section{RESULTS AND DISCUSSION}

\section{A. Simulation Results}

Return loss defines the delivering of the electrical energy from feed point to an antenna. To have full energy transfer, it is requisite to have negative return loss [13]. Figure 4 depicts the graph of return loss (dB) against frequency $(\mathrm{GHz})$. The simulated return loss results are $35,80 \mathrm{~dB}$ at the the center frequency of $3.2 \mathrm{GHz},-10,39$ $\mathrm{dB}$ at left side frequency of $3.18 \mathrm{GHz}$, and $-10.40 \mathrm{~dB}$ for right side frequency of $3.22 \mathrm{GHz}$. This result indicates that the proposed antenna design can efficiently transmit or receive a signal at the range of $3.18-3.22 \mathrm{GHz}$, since the return loss is below the commercially accepted return loss of $-9.54 \mathrm{~dB}$ at this range frequency. The simulation results are outlined in Table 3. The center frequency is $3.2 \mathrm{GHz}$ with the bandwidth of $40 \mathrm{MHz}$.

\section{B. Measurement Results}

After the fabrication of the proposed antenna, the antenna parameters are measured using Anritsu MS46322A Vector Network Analyzer (VNA) that has frequency range up to $40 \mathrm{GHz}$. The antenna operating frequency is in the range of $3-3.4 \mathrm{GHz}$. The measurement process was carried out at four different bending angles scenarios including $0^{\circ}, 30^{\circ}, 60^{\circ}$, and $90^{\circ}$ as shown in Figure 5.

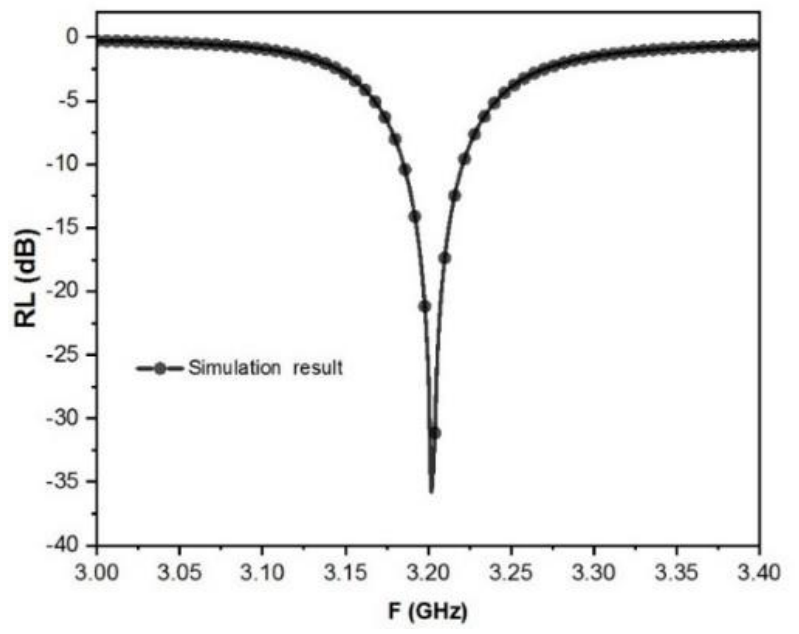

Figure 4. Response Return Loss from the simulation

TABLE 3

SIMULATION RESPONSE OF DESIGNED ANTENNA

\begin{tabular}{|l|l|}
\hline \multicolumn{1}{|c|}{ Specifications } & \multicolumn{1}{c|}{ Response } \\
\hline Type Antenna & Conformal \\
\hline Range Frequency & $3 \mathrm{GHz}-3.4 \mathrm{GHz}$ \\
\hline Substrate & Pyralux FR 9111 \\
\hline $\mathrm{f}_{1}$ (side left graph) & $3.18 \mathrm{GHz}$ \\
\hline $\mathrm{f}_{\mathrm{c}}$ (center frequency) & $3.20 \mathrm{GHz}$ \\
\hline $\mathrm{f}_{2}$ (side right graph) & $3.22 \mathrm{GHz}$ \\
\hline Return Loss $\mathrm{f}_{1}$ & $-10.39 \mathrm{~dB}$ \\
\hline Return Loss $\mathrm{f}_{\mathrm{c}}$ & $-35.80 \mathrm{~dB}$ \\
\hline Return Loss $\mathrm{f}_{2}$ & $-10.40 \mathrm{~dB}$ \\
\hline Bandwidth & $40 \mathrm{MHz}$ \\
\hline
\end{tabular}




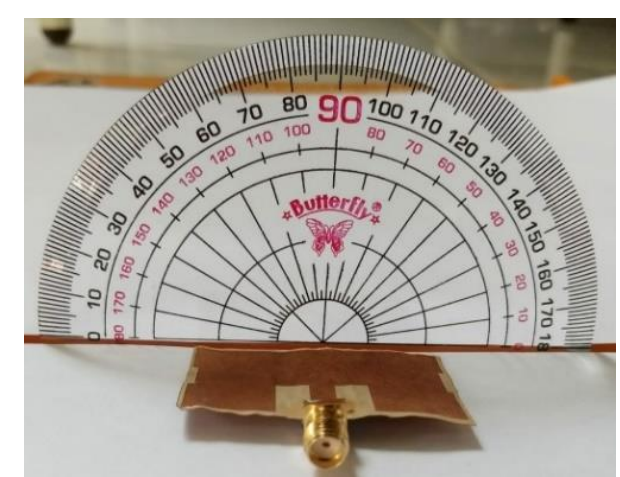

(a)

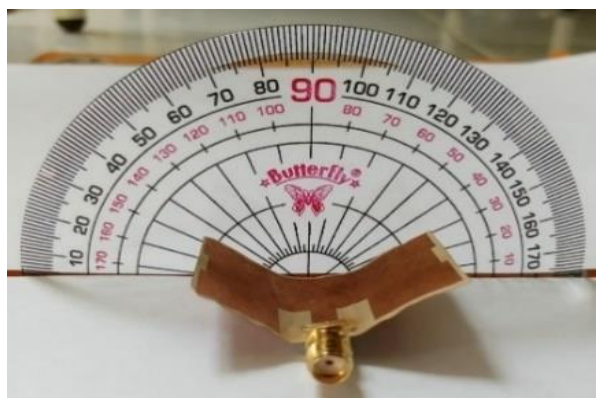

(b)

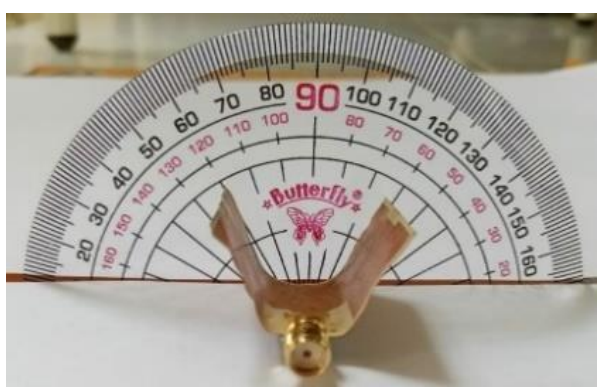

(c)

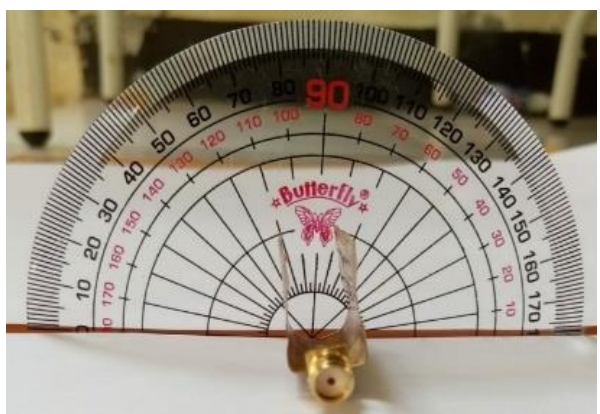

(d)

Figure 5. Measurement of conformal microstrip antenna at different bending angles: (a) $0^{\circ}$, (b) $30^{\circ}$, (c) $60^{\circ}$, (d) $90^{\circ}$.

\section{1) Return Loss, Bandwidth, and Impedance}

Figure 6 illustrates the comparison of return loss $\left(R_{\mathrm{L}}\right)$ from simulation and measurement of the proposed antenna at different bending angles. It can be seen from this Figure that the simulation and the measurement give different results in return loss and center frequency. This difference is possibly caused by different value of dielectric constant $\left(\varepsilon_{\mathrm{r}}\right)$ and wavelength $(\lambda)$ of the substrate, as well as the change in the thickness of the conductor patch layer during the PCB etching process. The simulation result displays $3.20 \mathrm{GHz}$ as center frequency, while the realization center frequency is shifted to higher frequency of $3.28 \mathrm{GHz}$ but still remain the same at various conformal status.

The measurement with various bending angles of $0^{\circ}$, $30^{\circ}, 60^{\circ}$, and $90^{\circ}$ have the same shape and peak frequency. However, the measured return loss for different conformal status has slightly different values. The antenna exhibits the smallest measured return loss of $-29.02 \mathrm{~dB}$ at the bending angle of $0^{\circ}$ and the highest value of $-31.38 \mathrm{~dB}$ at the bending angle of $90^{\circ}$.

Bandwidth of antenna is defined as the range between upper cut and lower cut of frequency, both at 10 $\mathrm{dB}$, which indicates range frequency where the antenna performs satisfactory. From Figure 6, it can be seen that the center frequency of realized antenna is shifted from $3.20 \mathrm{GHz}$ in simulation to $3.28 \mathrm{GHz}$ for all bending angles scenarios. The bandwidth for measured angles $0^{\circ}$, $60^{\circ}$, and $90^{\circ}$ is $80 \mathrm{MHz}$, while for bending angle of $30^{\circ}$, the measured bandwidth is $90 \mathrm{MHz}$.

Figure 7 shows antenna impedance characteristics of all bending angles scenarios in the Smith-Chart. It can be seen that the impedance circles for all bending angles have similar impedance value, which are quite close to impedance characteristic of transmission line $(50 \Omega)$. As the impedance is close enough to the transmission line impedance, it can be said that the antenna has maximum power transfer which leads to good performance in transmitting and receiving information signal. Table 4 summarizes the measurement results of antenna characteristics. Overall, the best performance was achieved by the scenario of bending angle $90^{\circ}$, in which $R_{\mathrm{L}}=-31.38 \mathrm{~dB}$ at $3.29 \mathrm{GHz}$, the bandwidth is $80 \mathrm{MHz}$, and the impedance $Z_{\mathrm{A}}=48.36+\mathrm{j} 2.04 \Omega$. Even though the simulation and measurement give slightly different results, the parameters can be considered well enough.

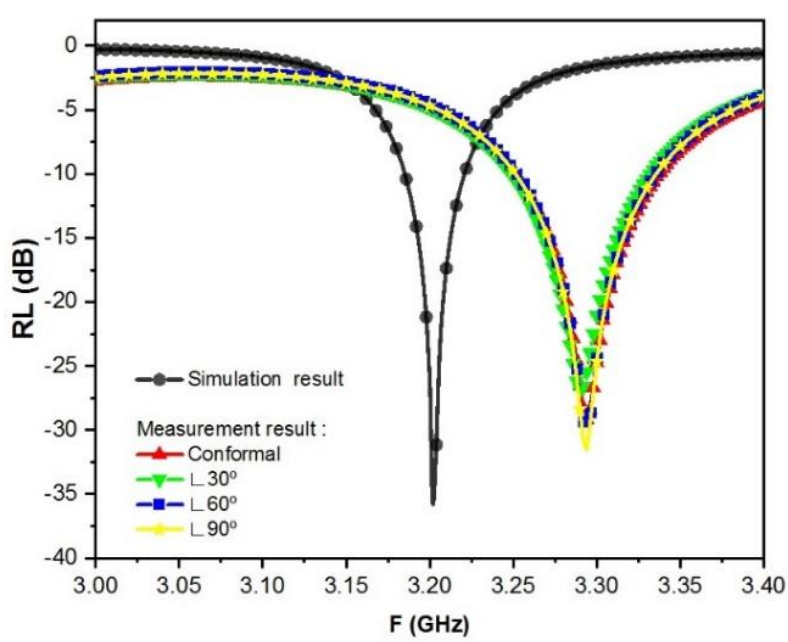

Figure 6. Simulation and measurement result of $\mathrm{R}_{\mathrm{L}}$ responses 


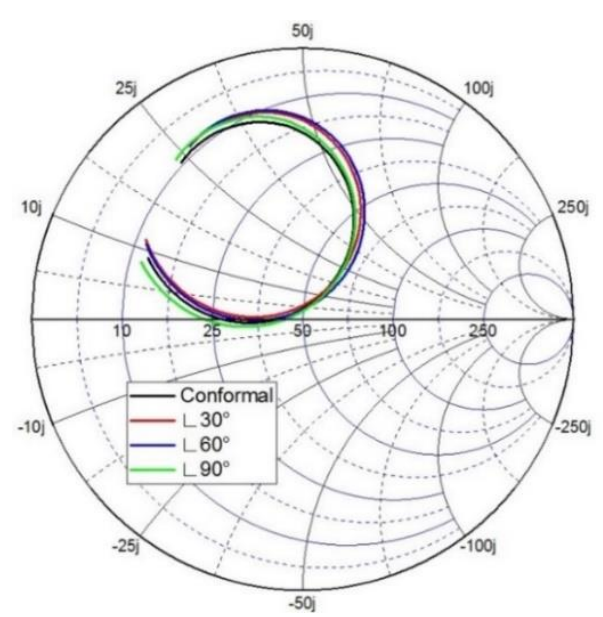

Figure 7. Impedance $\left(\mathrm{Z}_{\mathrm{A}}\right)$ of conformal microstrip antenna at bending angels of $0^{\circ}, 30^{\circ}, 60^{\circ}, 90^{\circ}$

TABLE 4

MEASUREMENT RESULTS OF ANTENNA CHARACTERISTICS AT FREQUENCY RANGE OF $3-3.4 \mathrm{GHZ}$

\begin{tabular}{|l|c|c|l|l|}
\hline Specifications & \multicolumn{4}{|c|}{ Response } \\
\hline $\begin{array}{l}\text { Bending } \\
\text { angles }\end{array}$ & $0^{\circ}$ & $30^{\circ}$ & $60^{\circ}$ & $90^{\circ}$ \\
\hline $\mathrm{f}_{1}$ & $3.25 \mathrm{GHz}$ & $3.24 \mathrm{GHz}$ & $3.25 \mathrm{GHz}$ & $3.25 \mathrm{GHz}$ \\
\hline $\mathrm{f}_{\mathrm{c}}$ & $3.29 \mathrm{GHz}$ & $3.29 \mathrm{GHz}$ & $3.29 \mathrm{GHz}$ & $3.29 \mathrm{GHz}$ \\
\hline $\mathrm{f}_{2}$ & $3.33 \mathrm{GHz}$ & $3.33 \mathrm{GHz}$ & $3.33 \mathrm{GHz}$ & $3.33 \mathrm{GHz}$ \\
\hline Return Loss $\mathrm{f}_{1}$ & $-10.20 \mathrm{~dB}$ & $-10.04 \mathrm{~dB}$ & $\begin{array}{l}-10.00 \\
\mathrm{~dB}\end{array}$ & $\begin{array}{l}-10.04 \\
\mathrm{~dB}\end{array}$ \\
\hline Return Loss $\mathrm{f}_{\mathrm{c}}$ & $-29.02 \mathrm{~dB}$ & $-26.80 \mathrm{~dB}$ & $\begin{array}{l}-29.60 \\
\mathrm{~dB}\end{array}$ & $\begin{array}{l}-31.38 \\
\mathrm{~dB}\end{array}$ \\
\hline Return Loss $\mathrm{f}_{2}$ & $-10.02 \mathrm{~dB}$ & $-10.09 \mathrm{~dB}$ & $\begin{array}{l}-10.03 \\
\mathrm{~dB}\end{array}$ & $\begin{array}{l}-10.08 \\
\mathrm{~dB}\end{array}$ \\
\hline Bandwidth & $80 \mathrm{MHz}$ & $90 \mathrm{MHz}$ & $80 \mathrm{MHz}$ & $80 \mathrm{MHz}$ \\
\hline $\begin{array}{l}\text { Impedance } \\
\left(\mathrm{Z}_{\mathrm{A}}\right)\end{array}$ & 48.37 & $\begin{array}{l}48.31 \\
+\mathrm{j} 4.13\end{array}$ & $\begin{array}{l}48.42 \\
+\mathrm{j} 2.7\end{array}$ & $\begin{array}{l}48.36 \\
+\mathrm{j} 2.04\end{array}$ \\
\hline
\end{tabular}

\section{2) Radiation Pattern}

Figures 8(a)-(d) show measurement results of antenna radiation patterns in various conformal states. Figure 8(a) shows measured radiation patterns at initial state, where the antenna is in flat position with bending angle of $0^{\circ}$. The best signal reception level is achieved at the angle of $0^{\circ}$ with the value of $-69 \mathrm{dBm}$. The smallest level of signal reception is $-92.87 \mathrm{dBm}$ at $230^{\circ}$. For bending angle of $30^{\circ}$ as depicted in Figure 8(b), the signal reception level ranges from $-86.12 \mathrm{dBm}$ to $-74 \mathrm{dBm}$. The level varies from of $-65.49 \mathrm{dBm}$ to $-55.4 \mathrm{dBm}$ as shown in Figure 8(c) for conformal state with bending angle of $60^{\circ}$. Figure $8(d)$ illustrates the measured signal reception levels for conformal state with bending angle of $90^{\circ}$. The smallest level is $-86.6 \mathrm{dBm}$ at $170^{\circ}$ and the highest level is -70.9 at $0^{\circ}$. The maximum realized gain is $1.4 \mathrm{dBi}$.

\section{CONCLUSION}

A single path conformal microstrip antenna at Sband frequency has been designed, manufactured and measured. Even though the experimental results have slightly difference from the simulation results, the proposed antenna still can operate in the targeted frequency since other parameters that affect the antenna

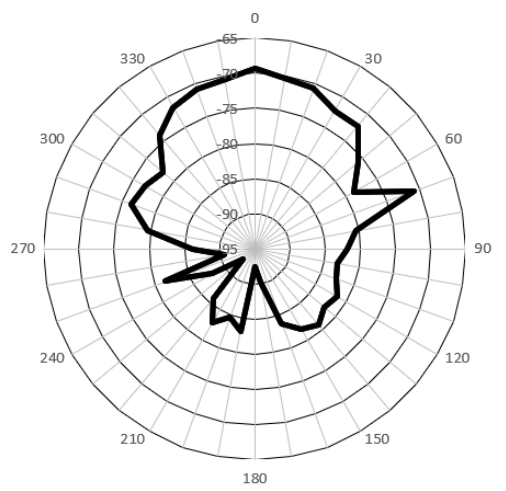

(a) bending angle of $0^{\circ}$

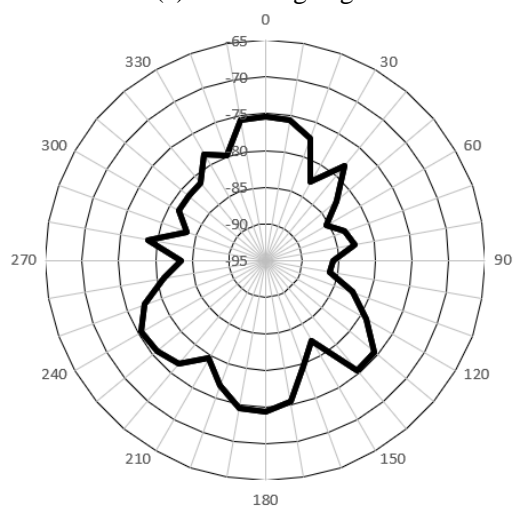

(b) bending angle of $30^{\circ}$

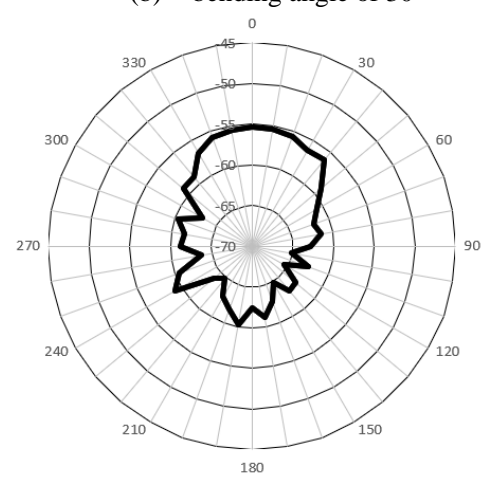

(c) bending angle of $60^{\circ}$

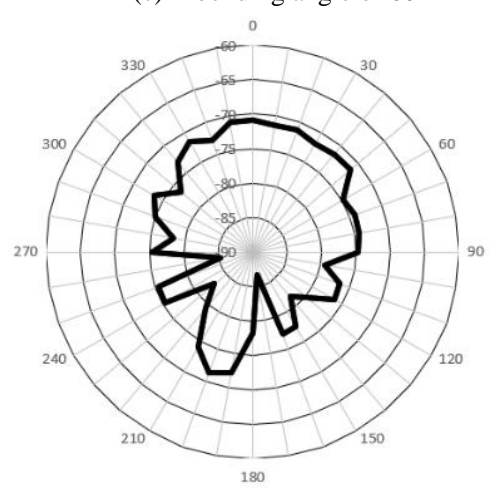

(d) bending angle of $90^{\circ}$

Figure 8. Radiation patterns at various conformal states.

performance are still in an acceptable condition. Operation frequency of the designed conformal patch antenna is $3.2 \mathrm{GHz}$, with return loss response of 29.02 $\mathrm{dB}$. Antenna measurement at different bending angles scenarios gives quite similar results with a considerable difference in return lost parameter. This indicates that the designed antenna can be used for various communication 
purposes in the S-Band frequency and can be etched to the various forms of devices.

\section{ACKNOWLEDGMENT}

This research was supported by the 2021 annual development project of LIPI (DIPA LIPI 2021).

\section{REFERENCES}

[1] F. Wang, et al., "Design of an ultra-thin absorption layer with magnetic materials based on genetic algorithm at the S band," Journal of Magnetism and Magnetic Materials, vol. 451, pp. 770773, Apr. 2018, https://doi.org/10.1016/j.jmmm.2017.12.025.

[2] M.N. Riaz, A. Buriro, A. Mahboob, "A defected ground based fractal antenna for C and S band applications," International Journal of Advanced Computer Science and Applications, vol. 10, no. 1, pp. 314-321, 2019.

[3] A. Kocakusak, S. Helhel, "Marble pre-selection chart to suppress EMF in S-Band and SAR reduction capabilities of them at $2.45 \mathrm{GHz}$," IETE Journal of Research, 2021, doi: 10.1080/03772063.2021.1972846.

[4] C. Doerr, et al., "O, E, S, C, and L band silicon photonics coheren modulator/receiver," in 2016 Optical Fiber Communications Conference and Exhibition (OFC), 2016, pp. 1-3.

[5] Z. Li, X. Zhu, and J. Zhang, "Fractal and conformal uwb antenna for wireless communication applications," in 2017 Sixth AsiaPacific Conf. Antennas Propag., 2017, pp. 1-3. doi: 10.1109/APCAP.2017.8420568.

[6] R. Parikh, P. Joshi, and A. Rawat, "Designing of rectangular microstrip patch antenna at $2.48 \mathrm{Ghz}$ frequency for IRNSS application," in Proc. 2018 2nd International Conference on
Electronics, Materials Engineering \& Nano-Technology (IEMENTech), 2018, pp. 1-3, doi: 10.1109/IEMENTECH.2018.8465174.

[7] E. Pittella, S. Pisa, A. Nascetti, "Reconfigurable S-band patch antenna radiation patterns for satellite missions," in Proc. 2018 5th IEEE International Workshop on Metrology for AeroSpace (MetroAeroSpace), 2018, pp. 651-656, doi: 10.1109/MetroAeroSpace.2018.8453576.

[8] K.C. Rao, P.M. Rao, "Design, simulation, analysis, fabrication and testing of integrated transmitting and receiving micro strip patch antennas for communicating with a satellite in S-band communication," in Proc. 2017 Progress in Electromagnetics Research Symposium-Fall (PIERS-FALL), 2017, pp. 2830-2873, doi: 10.1109/PIERS-FALL.2017.8293617.

[9] M.W. Majeed, A. Khan, A.U. Rehman, K. Rashid, "Microstrip patch antennas for microwave $\mathrm{S}$ band, $\mathrm{C}$ band and $\mathrm{X}$ band applications," Bahria University Journal of Information \& Communication Technology, vol. 4, no. 1, p. 36, 2011.

[10] M. Sebastian, "Measurement of microwave dielectric properties and factors affecting them," in Dielectric Materials for Wireless Communication, Elsevier Science, 2008, pp. 11-47.

[11] C. Balanis, Antenna Theory Design, Canada: Jhon Wiley \& Sons, Inc, 2006.

[12] D. Paragya, and H. Siswono, " $3.5 \mathrm{GHz}$ rectangular patch microstrip antenna with defected ground structure for 5G," Jurnal Teknik Energi Elektrik, Teknik Telekomunikasi, \& Teknik Elektronika, vol. 8, no. 1, pp. 32-42, Jan. 2020, doi: https://doi.org/10.26760/elkomika.v8i1.31.

[13] A. Jain, R. Goyal, and S. Kumar, "Return loss and bandwidth enhancement in antenna having imperfect ground plane," Journal of Xi'an University of Architecture \& Technology, vol. XII, issue V, pp. 1104-1111, 2020. 